\title{
Modelling of Alternative Borehole Configurations for Geo-Exchange
}

\author{
Ying Lam E. Law
}

\author{
Seth B. Dworkin
}

\begin{abstract}
During the operation of a ground source heat pump (GSHP), the ground acts as a heat sink and heat source in cooling and heating modes, respectively. When the heating and cooling loads are extremely unbalanced, ground temperature can slowly migrate up or down in the long term, diminishing the GSHP system's performance, and eventually causing the system to fail. This failure occurs when the ground can no longer accept or provide more heat for a building. Therefore, a method to mitigate thermal imbalance is needed.

Previous studies in the literature examine the effects of borehole configurations in geo-exchange. However, no study has been done to analyze the effects of varying borehole lengths in a bore field. The objective of this study is to examine the effects on thermal performance from changing the length of individual boreholes while retaining the same total borehole length. In this paper, the four centre boreholes in a $4 \times 4$ borehole system were shortened and the length of the remaining boreholes was recalculated to meet the total required ground loop length. A 20 year operation was simulated for a school building model with centre borehole lengths of $100 \mathrm{~m}, 80 \mathrm{~m}$, and $50 \mathrm{~m}$ and separation distances of $3 \mathrm{~m}, 4 \mathrm{~m}$, and $6 \mathrm{~m}$, to study the benefits of shortening the centre boreholes. The results demonstrate that by adjusting the length of the centre boreholes, separation can be reduced.
\end{abstract}

\section{INTRODUCTION}

Ground-source heat pump (GSHP) systems use the ground as a stable heat transfer medium to provide heating and cooling for a building. Heat is extracted/released into the ground during heating and cooling modes, respectively. Because the ground, approximately $10 \mathrm{~m}$ beneath the surface, remains at approximately the same temperature throughout seasonal fluctuations, it is a stable medium for heat transfer. When the heating and cooling demands of a building are balanced, ground temperature remains steady over time. However, when heating and cooling demands of a building are greatly imbalanced, ground temperature can slowly climb or decline. An increase (or decrease) in ground temperatures can cause a degradation in system performance because of the inefficient heat transfer temperatures. Many systems in the past had to stop operation because of low system efficiencies, making them uneconomic to operate.

Borehole configurations can play a major role in ground temperature changes. In many cases, borefield sizing is determined based on peak heating and cooling demands. Compensation for thermal imbalance is more of an afterthought and much more complex in practice. The problem of ground temperature change is still a problem in many installations due to costly overdesigns or degredation in functionality. Borehole performance is immediately affected by neighbouring boreholes (Koohi-Fayegh and Rosen 2012). Borehole systems with small separation distances experience more thermal interference between neighbouring boreholes than systems with greater separation distances (Koohi-Fayegh and Rosen 2012). The increase in separation distance can also increase the percentage of temperature restoration due to the reduction in borehole thermal interference (Yuan, et al. 2016). In addition, the temperature distribution of the borehole field can also be affected by borehole separation distances. When studying the temperatures at the centre, side, and corner of the borehole field, the greatest change in temperature can be found in the centre of the configuration. However, when borehole separation distances are increased, the difference between 
the temperatures at these locations are reduced (Yuan, et al. 2016).

While borehole separation is important in the design of geo-exchange, studies have shown that borehole separation distance is not the only factor that contributes to thermal imbalance. The study described in Law and Dworkin (2016) showed that by varying the aspect ratio of borehole configurations, ground temperature changes can be slightly alleviated. The increase in borehole field perimeter was able to slightly lower the changes in ground temperature due to the larger area available for heat to dissipate to the surrounding soil. The decrease in ground temperature change can allow the system to operate efficiently for a longer period of time.

In an array of boreholes, the centre boreholes of the configuration are most affected by thermal imbalance due to neighbouring borehole interactions. These boreholes are the least effective because of the poor heat transfer temperatures in the surrounding soil. A method to alleviate ground temperature change is to remove inner boreholes (Bayer, et al. 2014). In this method, the least effective boreholes (inner boreholes) were removed from the borehole field to prevent thermal accumulation in the centre of the borehole fields. The results in Bayer, et al. (2014) showed that the cavity created by the removal of inner boreholes contributed to better heat transfer, resulting in smaller changes in ground temperature. This method moves the location of thermal accumulation away from the centre of the borehole field.

Another method to alleviate the effects of thermal imbalance is to alter borehole configurations in the axial direction. Examples of this method include the installation of inclined boreholes (Marcotte and Pasquier 2009). During the construction phase of a GSHP system, instead of drilling boreholes vertically into the soil, boreholes can be drilled on an incline, away from the centre of the borehole field. A dip angle was defined as the angle at which the borehole is oriented away from the vertical direction. A reduction in temperate changes was observed by changing the dip angle of the boreholes (Marcotte and Pasquier 2009). In addition, borehole length savings were also achieved (Marcotte and Pasquier 2009). The inclination of boreholes pose a beneficial design in geo-exchange because their installation does no incur a greater cost in construction.

While most simulation methods use the superposition of $\mathrm{g}$-functions to determine the temperature distribution in a borehole field, these studies neglect axial effects. Axial effects are important in the simulation of boreholes especially in short borehole systems with unbalanced loads (Marcotte, et al. 2010). A study by Marcotte, et al. (2010) compared finite and infinite line-source models for the same borehole system. The infinite line-source model predicted a single temperature for the entire length of borehole, however, the finite line-source model predicted a gradient of temperatures approaching the infinite line-source temperature as the depth of the borehole increased. In the prediction of percentage borehole freezing, the discrepancy between the infinite and finite line-source models was $48 \%$ (Marcotte, et al. 2010). Due to the large discrepancies in the results of the two models, it is important to consider axial effects, especially in shallow boreholes.

Studies have indicated the importance of studying borehole separation distances, borehole configurations, and axial effects; there is a need to combine the effects of all three aspects in a borehole field. Borehole designs typically consist of various borehole field layouts of uniform length boreholes. However, no study has been done to assess the effect of operating a GSHP system with boreholes of varying length.

In this study, a 4x4 borehole configuration was studied. The four centre boreholes in the 16 borehole system were shortened and the length of the remaining boreholes was recalculated to maintain system capacity. A finiteelement model was created to demonstrate the operation of a 16 borehole system with varying borehole lengths. The simulation was computed for a 20 -year operating duration at hourly time-steps. Ten cases were simulated, each with different combinations of centre borehole length and borehole separation distance.

\section{METHODOLOGY}

This study consists of finite element modelling of alternative borehole configurations. The alternative borehole arrangement is illustrated in Figure 1. The centre four boreholes (depicted in grey) are shortened and the remaining boreholes (depicted in black) are extended relative to a base case. The borehole lengths used in this study are 
summarized in Table 1. For example, in the ' 80 ' configuration, the four centre boreholes are each $80 \mathrm{~m}$ in length and the remaining boreholes are each $106.67 \mathrm{~m}$.

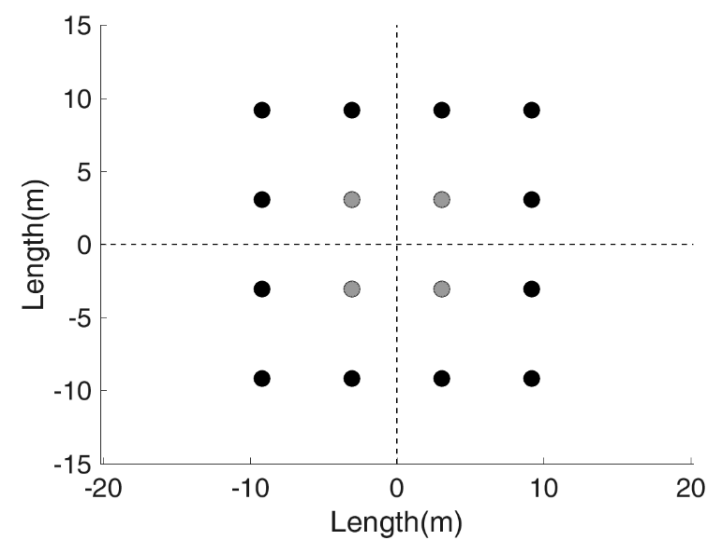

Figure 1 Alternative borehole arrangement layout

The test case is a high school building located in Toronto, Canada that had a GSHP considered. The GSHP was designed to meet $100 \%$ of the building's heating and cooling capacities. The peak loads of the building are 170 $\mathrm{kW}$ and $145 \mathrm{~kW}$ for cooling and heating, respectively. The "normal" sizing process is to determine the required ground loop length using the method presented by Kavanaugh \& Rafferty (1997) for equal borehole lengths.

Table 1. Borehole Lengths Summary

\begin{tabular}{ccc}
\hline Borehole configuration & Inner borehole length $(\mathbf{m})$ & Outer borehole length $(\mathrm{m})$ \\
\hline \hline 100 & 100 & 100 \\
80 & 80 & 106.67 \\
50 & 50 & 116.67 \\
\hline
\end{tabular}

First, hourly heating and cooling demands of a building were processed to obtain hourly borehole wall heat fluxes. Then, a finite element geometry as illustrated in Figure 1 was created in COMSOL Multiphysics (COMSOL Inc., 2016). Hourly heat fluxes were applied to the borehole walls to simulate a borehole providing heating and cooling for a building. The operation of the system was simulated for a 20 year period with hourly time steps. The results of the simulation are presented in the following sections.

\section{Model Set Up}

The method employed to determine the hourly heat flux is the same as the one used in (Law and Dworkin, 2016). The variation in COP during the operation of the GSHP was not considered in this study. Since the purpose of this study was to compare the various ground loop configurations, constant COPs were used since they would affect the test cases similarly. Although applying variable COPs may change the quantitative results, it is unlikely that they will greatly impact the qualitative comparisons presented in this study. Hourly heating and cooling demands were processed into hourly heat fluxes using MATLAB (MathWorks Inc., 2016). Positive heat flux represents the release of heat into the borehole field and negative heat flux represents the extraction of heat from the borehole field. The hourly heat flux was calculated by determining the hourly "ON" and "OFF" cycles of the heat pump. For every hour that the heat pump is turned "ON", the maximum heating or cooling capacity is provided. For every hour that heating 
or cooling is not required, the system turns "OFF". Residual heating or cooling from the previous hour can be used to supply the building with heating or cooling when the system is "OFF". For example, if $10 \mathrm{kWh}$ of heating is the capacity of the heat pump and the heating demand of the building for the first two hours are $5 \mathrm{kWh}$ each, the GSHP can turn "ON" for the first hour and be "OFF" for the second hour. The same approach as in (Law and Dworkin, 2016) was taken to calculate the hourly heat flux, upon determining the "ON" and "OFF" cycles of the heat pump.

\section{Test case and simulation properties}

The test case used in this analysis is a school building with slightly unbalanced heating and cooling loads. While a variation in borehole lengths can slightly reduce the effects of thermal imbalance, highly unbalanced loads are not recommended due to their large thermal impact on the soil. The net heating and cooling demands of this building can be found in Figure 2. The heating and cooling demands of the school building exhibit an interesting pattern in which the cooling demands drop significantly in the summer months when the occupancy of the school is low.

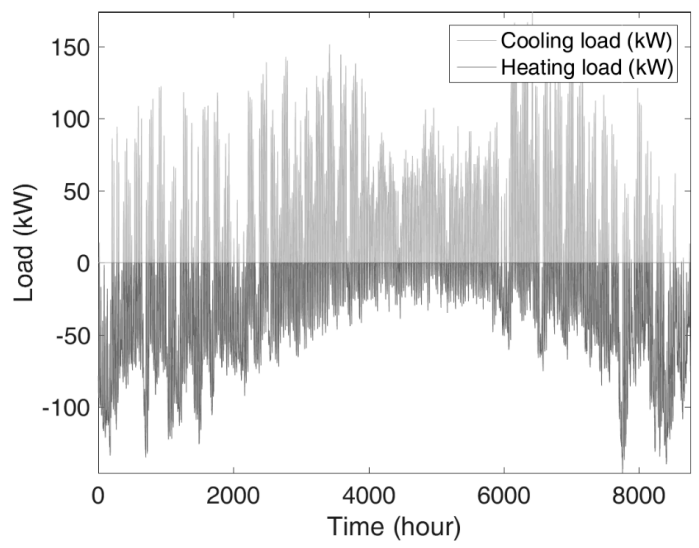

Figure 2 Net heating and cooling demands of a school building.

Using the same calculation method as outlined in (Law and Dworkin, 2016), the hourly heat fluxes were determined based on the hourly heating and cooling demands. The GSHP system was sized to its maximum heating and cooling capacities. The flow rate in all boreholes are considered to be constant and at system capacity. A simple on-off logic is used to maintain building comfort. Although variable speed pumps with varying system capacity are now available, in practice the majority of systems still operate in on-off scenarios using single speed pumps. Since the characteristic time of heat dissipation through the ground is much greater than that of on-off switching, the impact of this assumption is expected to be negligible. At each hour, it was determined whether the system was "ON" for heating, "ON" for cooling or "OFF" for both. It was assumed that turning the system "ON" would supply a building with its maximum capacity.

The heating and cooling systems" "ON" and "OFF" conditions were determined for each of the 8760 hours of the year and hourly heat fluxes are calculated based on these conditions. The hourly heat fluxes for the school building are presented in Figure 3. Lines in dark gray represent positive heat flux where heat is transferred into the ground. Lines in light gray represent negative heat fluxes where heat is extracted from the ground. "ON" and "OFF" cycles of the system can be observed in Figure 3 by the occasional spacing between hours. 


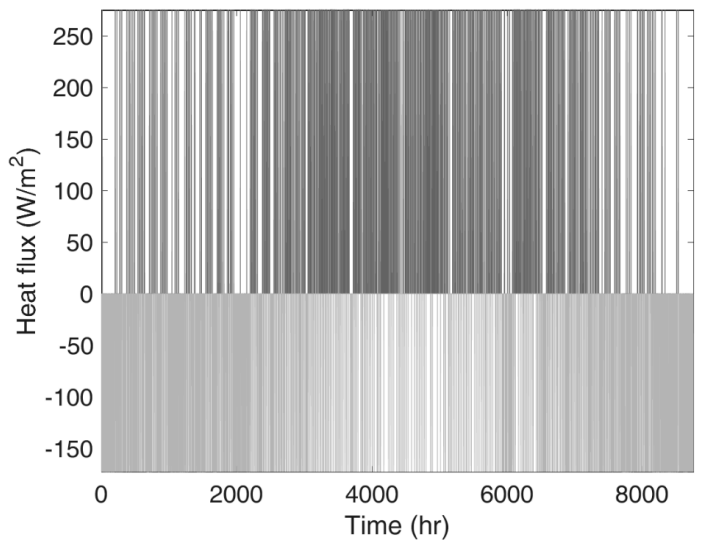

Figure 3 Hourly heat flux of school building

The simulation was conducted in COMSOL Multiphysics for a 20 year period at hourly time steps (COMSOL Inc., 2016). At each hour, the boundary heat flux condition at the borehole walls are updated with the hourly heat fluxes calculated in the previous step. A quarter of the simulation domain was created to model 4 operating boreholes. Symmetry conditions were applied to two faces to mirror the domain. Using the symmetry conditions, a 16 borehole system can be simulated by only modelling 4 boreholes. This simplification of geometry allowed for a reduction in computation time. Open boundary conditions were applied to the remaining faces to model far-field conditions.

The simulation was repeated for 9 different cases of borehole configurations. The configurations are selected based on combinations of different borehole spacing and centre borehole length as presented in Table 2. For example, case 2 is a 16 borehole installation in a $4 \times 4$ configuration. The inner 4 boreholes in the system are $80 \mathrm{~m}$ in length and the remaining 12 are $106.67 \mathrm{~m}$ in length. The $3 \mathrm{~m}$ borehole spacing indicates that the boreholes are spaced $3 \mathrm{~m}$ apart from each other.

Table 2. Borehole configurations

\begin{tabular}{ccc}
\hline Case & Borehole spacing $(\mathbf{m})$ & Centre borehole length $(\mathbf{m})$ \\
\hline \hline 1 & 3 & 100 \\
2 & 3 & 80 \\
3 & 3 & 50 \\
4 & 4 & 100 \\
5 & 4 & 80 \\
6 & 4 & 50 \\
7 & 6 & 100 \\
8 & 6 & 80 \\
9 & 6 & 50 \\
10 & 5 & 50 \\
\hline
\end{tabular}

\section{RESULTS}

\section{Borehole wall temperature}

In this simulation the temperature at a point near the borehole wall is studied. This temperature is extracted 
from a point $1 \mathrm{~cm}$ away from the borehole wall (point A). The location of $1 \mathrm{~cm}$ was chosen because it is very close to the borehole wall, and therefore can represent borehole wall temperature. A parallel line $1 \mathrm{~cm}$ away from the borehole wall was considered along each borehole and the average temperatures of those lines were calculated. The yearly average borehole wall temperature were calculated and summarized in Figure 4.

In Figure 4, three cases are presented. The three cases have centre borehole lengths of $100 \mathrm{~m}$ and vary in separation distance $(3 \mathrm{~m}, 4 \mathrm{~m}$, or $6 \mathrm{~m})$. Figure $4 \mathrm{~b}$ and Figure $4 \mathrm{c}$ are similar for centre borehole lengths of $80 \mathrm{~m}$ and 50 $\mathrm{m}$, respectively. From the figures, it is evident that the borehole wall temperatures are highest in the case with the $3 \mathrm{~m}$ separation distance and lowest in the case with the $6 \mathrm{~m}$ separation distance.

a)

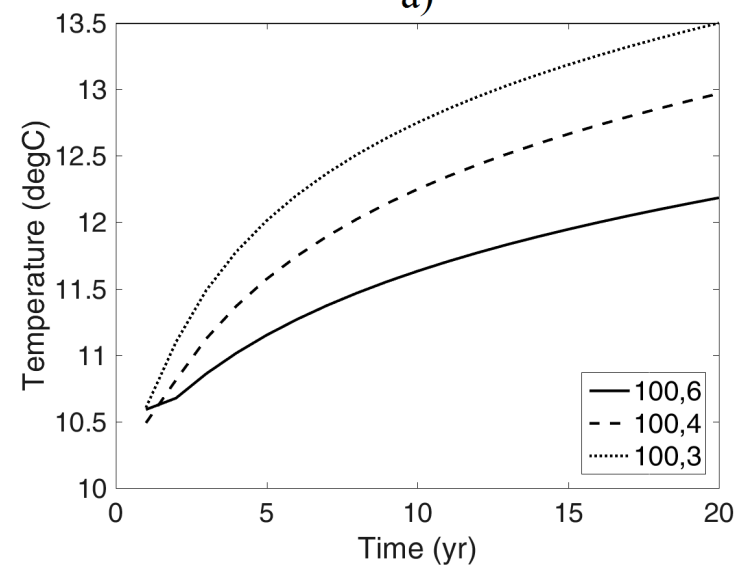

b)

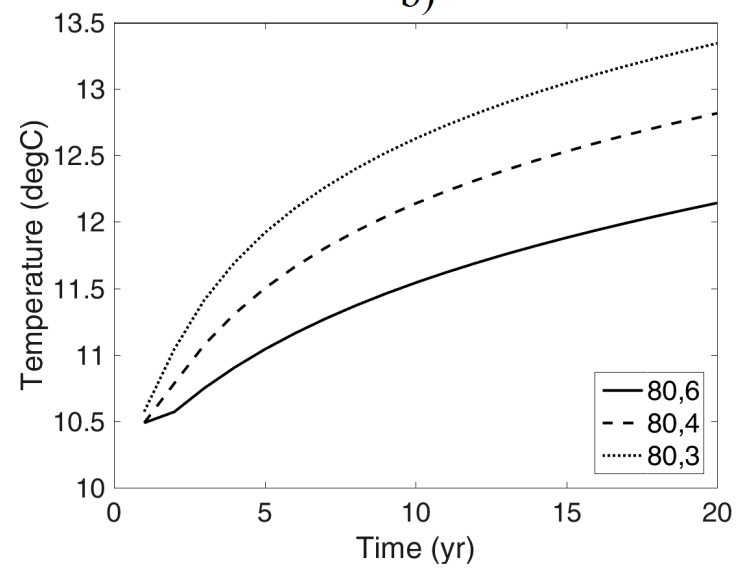

c)

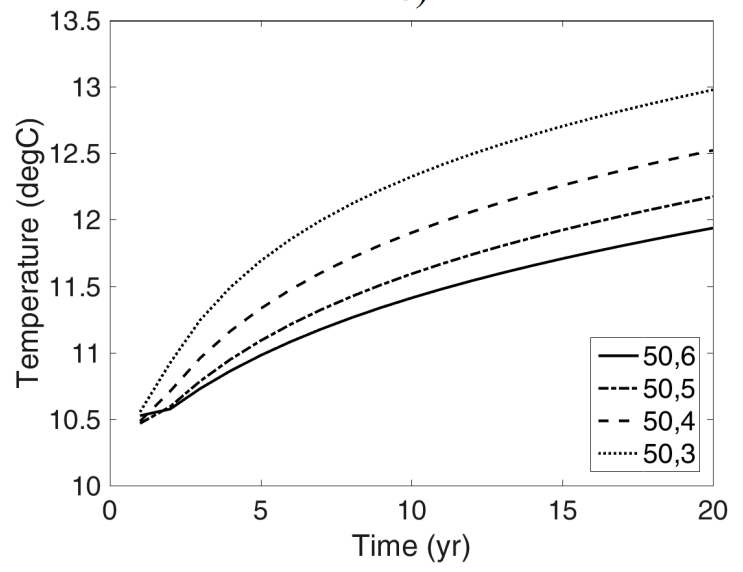

Figure 4 Average temperature at point A for a) $100 \mathrm{~m}$, b) $80 \mathrm{~m}$, and c) $50 \mathrm{~m}$ centre borehole length configurations

In Figure 4c, it is interesting to note that the temperature difference between the $3 \mathrm{~m}$ and $4 \mathrm{~m}$ separation distance is significantly greater than the temperature difference between the $5 \mathrm{~m}$ and $6 \mathrm{~m}$ cases. The rate of increase in ground temperature is higher when separation distance is small and is lower when the separation distance is greater. The rate of increase in ground temperature is higher when separation distance is small because there is less soil volume available between boreholes for heat to dissipate to.

The effects of varying borehole lengths were also studied. The results are presented in Figure 5 for the cases with $4 \mathrm{~m}$ borehole separation distances. The plots for $3 \mathrm{~m}$ and $6 \mathrm{~m}$ separation distances are not presented in this 
analysis because of their similarities with Figure 5. In Figure 5, the average temperatures at point A were studied for three borehole configurations. It can be observed from the figure that the " 50 " configuration has a smaller increase in temperature compared to the " 80 " and " 100 " configurations over the 20 year study period. Thermal benefits in using the " 50 " configuration can be observed. Using the same amount of drilling and piping, over 20 years, the "50"

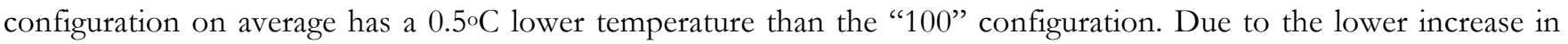
borehole wall temperature, more effective heat transfer and better COP managemenent can occur.

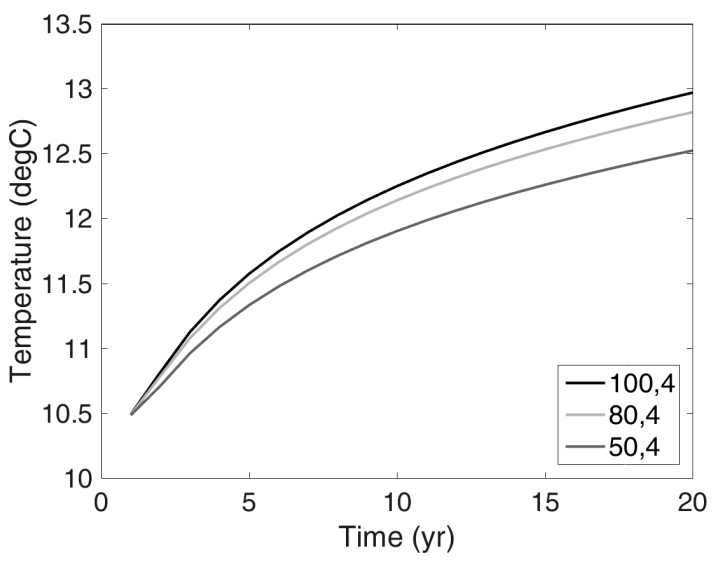

Figure 5 Average temperature at point $\mathrm{A}$ at $4 \mathrm{~m}$ separation distance

\section{Alternative designs}

In the hopes of developing ways to alleviate the effects of thermal imbalance, the ground temperature changes in all 10 configurations indicated in Table 2 were compared. Annual average temperatures were calculated for 20 years for each system and summarized in Figure 6. Based on the results in this figure, it can be noticed that ground temperature increases with decreasing separation distance and increasing centre borehole length. As borehole wall temperature increases, ground temperature also increases due to the heat dissipated from the borehole wall into the surrounding soil. Although in all cases, ground temperature increases as time increases, the overlapping/shadowing lines may lead to potential alternative designs.

Several potential designs can be considered based on the results presented in Figure 6. If a GSHP system was originally designed with a uniform borehole field (100 m boreholes) with separation distance of $6 \mathrm{~m}$ (100, 6 in figure), alternative configurations can be determined using lines near the proposed design line in Figure 6. For example, a "50, 6" design can be used to reduce the ground temperature increase.

Alternatively, based on the simulation results, a " 50,5 " design can be proposed. It can be observed that the behaviour of his line is very similar to the original "100, 6" design. This new design would decrease borehole spacing, allowing the system to be installed in a smaller space. This finding can provide potential designs for buildings that have property sizes that are determined to be insufficient for installation of GSHP systems. 


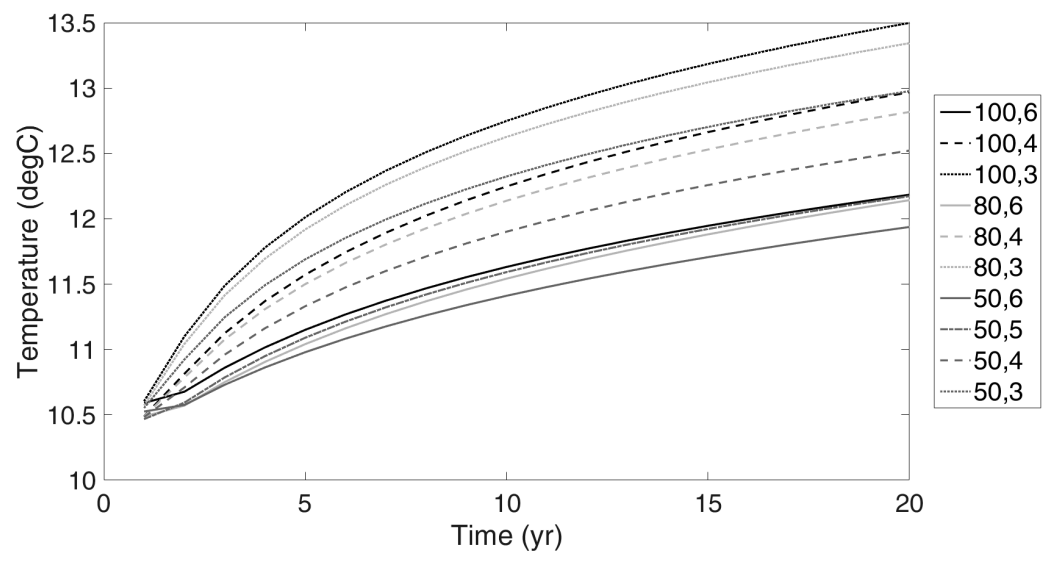

Figure 6 Summary of all simulation results

\section{CONCLUSIONS}

Although studies have previously been done to characterize the effects of borehole geometry in terms of borehole field arrangements and borehole separation distance, little research had been done to explore the effects of alternating the length of boreholes. To fill the knowledge gap in the study of borehole lengths, a series of simulations were performed in this work.

The operation of a $4 \times 4$ configuration borehole field with varying borehole lengths and borehole separation distance was simulated. Although variable speed pumps are available, an on-off scenario with single speed pumps was modeled in this study as many systems still operate using this technology. Ten cases were studied and an increase in ground temperature near the borehole wall can be observed with the decrease of borehole separation distance. In addition, an increase in ground temperature near the borehole wall can also be observed with the increase of inner borehole depth. It was observed from the present results that alternative designs can be used to achieve the same ground temperature change with uniform borefield lengths. Specifically, it was found that the configuration with inner borehole length of $50 \mathrm{~m}$ at a separation distance of $5 \mathrm{~m}$ behaved similarly as the configuration with inner borehole length of $100 \mathrm{~m}$ at a separation distance of $6 \mathrm{~m}$. This result indicates that borehole separation distance can be reduced by alternating the borehole lengths of a system. This reduction can allow GSHP systems to be installed in smaller spaces, which is beneficial to locations where land prices are high, or properties are dense.

This study demonstrated the importance of the study of alternative borehole configurations. Alternative borehole configurations can be used to reduce the effects of ground thermal imbalance. To fill the knowledge gap present in this study, further study should be performed on the effects of alternating borehole lengths in other borehole field arrangements. The study of varying borehole lengths should be extended to incorporate different borehole field layouts. In addition, refined details should be added to the current model to develop models that are more representative of operating GSHP systems. Such details should include but not limited to fluid flow inside pipes, additional soil properties and varying COPs.

\section{ACKNOWLEDGEMENTS}

The authors would like to thank the Faculty of Engineering and Architectural Science at Ryerson University, Ontario Centres of Excellence (OCE), Ontario Graduate Scholarship (OGS), Queen Elizabeth II Graduate Scholarships in Science and Technology (QEII-GSST), McClymont and Rak Engineers, the Centre of Urban Energy at Ryerson University, and the Enwave Corporation for financial support. 


\section{REFERENCES}

Bayer, P., M. dePaly, and M. Beck. 2014. "Strategic optimization of borehole heat exchanger field for seasonal geothermal heating and cooling." Applied Energy 136: 445-453.

COMSOL Inc. 2016. COMSOL Multiphysics. http://www.comsol.com.

Koohi-Fayegh, S., and M.A. Rosen. 2012. "Examination of thermal interaction of multiple vertical ground heat exchangers." Applied Energy 97: 962-969.

Law, Y.L.E., and S.B. Dworkin. 2016. "Characterization of the effects of borehole configuration and interference with long term ground temperature modelling of ground source heat pumps." Applied Energy 179: 1032-1047.

Marcotte, D., and P. Pasquier. 2009. "The effect of borehole inclination on fluid and ground temperature for GLHE systems." Geothermics 38: 392-398.

Marcotte, D., P. Pasquier, F. Sheriff, and M. Bernier. 2010. "The importance of axial effects for borehole design of geothermal heat-pump systems." Renewable Energy 35: 763-770.

MathWorks Inc. 2016. MATLAB. http://www.mathworks.com.

Yuan, Yanping, Xiaoling Cao, Junqing Wang, and Liangliang Sun. 2016. "Thermal interaction of multiple ground heat exchangers under different intermittent ratio and separation distance." Applied Thermal Engineering 108: $227-286$. 